\title{
The Impact of Socioeconomic Status on the Use of Adjuvant Radioactive Iodine for Papillary Thyroid Cancer
}

\author{
Jose P. Zevallos, ${ }^{1} \mathrm{Li} \mathrm{Xu},{ }^{2}$ and Yin Yiu ${ }^{1}$
}

Introduction: The effect of socioeconomic status (SES) on thyroid cancer treatment has not been studied extensively. The purpose of this study is to determine the impact of SES on the use of adjuvant radioactive iodine (RAI) after total thyroidectomy for papillary thyroid cancer (PTC). We hypothesize that patients of low SES are less likely to receive RAI after total thyroidectomy.

Methods: Case characteristics of 9011 patients with PTC $\geq 1 \mathrm{~cm}$ in size and undergoing total thyroidectomy were extrapolated from the Surveillance, Epidemiology and End Results database. Chi-square test and multivariate analyses were performed to compare demographics, clinicopathologic features, and use of RAI by county-level measures of SES.

Results: Low-SES patients were more likely to present with positive lymph nodes in the <45-year age group and with advanced American Joint Committee on Cancer stage, positive lymph nodes, multifocal tumors, extrathyroidal extension, and larger tumors in the $\geq 45$-year age group. Among patients $<45$ years of age, those from counties with a higher median household income and a higher SES composite score had significantly higher rates of RAI use (odds ratio [OR] 1.36 [95\% confidence interval (CI) 1.09-1.70], $p=0.006$, and OR 1.29 [CI 1.111.49 ], $p<0.001$, respectively). Among patients $\geq 45$ years of age, those residing in counties with higher education levels were associated with higher rates of RAI use (OR 1.27 [CI 1.05-1.54], $p=0.015$ ), while the association between SES composite score and RAI use approached statistical significance (OR 1.13 [CI 1.00-1.28], $p=0.053$ ). Conclusions: This study demonstrates that low SES is associated with more advanced PTC at presentation and a lower rate of adjuvant RAI after total thyroidectomy, particularly among patients $<45$ years of age from areas with a low median household income. Future studies are needed to address these disparities, as well as to determine appropriate indications for the use of adjuvant RAI for PTC.

\section{Introduction}

$\mathbf{S}$ OCIOECONOMIC STATUS (SES) has been shown to be strongly associated with access to health care. It has been demonstrated that people with low SES have less access to preventative health services, primary care physicians, health screening, and treatment (1). For patients of low SES with cancer, this often translates into more advanced tumors at presentation and worse oncologic outcomes. This has been demonstrated in a variety of cancer sites, including lung, breast, and colon (1-3).

SES has also been shown to play an important role in thyroid cancer incidence, presentation, and outcomes. Previous studies have noted that areas with less access to health care (4) and lower SES (5) have a lower incidence of thyroid cancer, likely as a result of less surveillance in these communities. Low SES has also been associated with more ad- vanced thyroid cancer stage at presentation $(6,7)$. While the impact of SES on thyroid cancer incidence and stage at presentation has been reported, the effect of SES on thyroid cancer treatment has not been clearly elucidated.

Radioactive iodine (RAI) is widely used as adjuvant therapy after total thyroidectomy for well-differentiated thyroid cancer (8). While guidelines advocate the use of RAI for advanced or high-risk thyroid cancer (9), the use of RAI is controversial and significant variation in treatment patterns exists. The use of RAI varies by several factors unrelated to thyroid cancer stage or severity, including race/ethnicity, hospital type and case volume, and hospital region (10). The purpose of this study is to determine the impact of SES on the use of RAI for papillary thyroid cancer (PTC). We hypothesize that low SES is associated with lower rates of RAI use after total thyroidectomy for patients with PTC.

${ }^{1}$ Bobby R. Alford Department of Otolaryngology/Head and Neck Surgery, Baylor College of Medicine, Houston, Texas.

${ }^{2}$ Department of Head and Neck Surgery, University of Texas MD Anderson Cancer Center, Houston, Texas. 


\section{Methods}

\section{Data sources and patient selection}

The study design was a retrospective cohort analysis utilizing the Surveillance, Epidemiology, and End Results (SEER) database, a registry maintained and updated annually by the National Cancer Institute. Specifically, we employed the dataset named "Incidence - SEER 18 Regs Research Data + Hurricane Katrina Impacted Louisiana Cases, Nov 2011 Sub (1973-2009 varying).', This particular database contains incidence research records for 18 geographic areas that collectively span approximately $28 \%$ of the U.S. population. Since SEER is a public database without patient identifiers, this study was granted an exemption from the Baylor College of Medicine Institutional Review Board.

Eligible patients were identified using the International Classification of Diseases for Oncology (3rd edition), histology codes encompassing the clinically relevant subtypes of PTC. Thyroid cancer codes included were those for papillary carcinoma (8050) and papillary adenocarcinoma (8340-8344). Then, we further selected for cases with adequate data regarding staging, primary surgery, nodal management, and use of RAI. As the most recent American Joint Committee on Cancer (AJCC) (11) staging groups were gathered for patients after the year 2004, our study examines patients from 2004 to 2009. American Thyroid Association guidelines only recommend further evaluation of thyroid nodules above a threshold of $1 \mathrm{~cm}$ (9). Therefore, patients with tumors less than $1 \mathrm{~cm}$ in size were excluded from the study. As this study examined the use of adjuvant RAI, only patients undergoing total thyroidectomy were included in this study.

Our definitive case listing extrapolated from SEER included demographic variables such as patient age, sex, month and year of diagnosis, marital status at presentation, and race/ ethnicity (non-Hispanic White, African American, Hispanic, and Asian). Clinicopathologic characteristics of the tumors included AJCC stage, tumor size in millimeters, tumor extension, histologic classification, number of examined and subsequently positive lymph nodes, and designation of lesions as solitary versus multifocal.

County-level data on SES were collected using SEER*Stat software as previously described by Li et al. (5). In brief, three county SES indicators (cost-of-living-adjusted median household income, proportion of residents with at least a high school education, and percentage of population with health insurance) were coded in quartiles and given equal weight to produce a composite SES score. For the analysis, these socioeconomic variables were categorized as either lowest quartile ("low") or top three quartiles ("high"), as has been previously reported in other studies examining the effects of SES on cancer $(5,12)$. The SES composite score was similarly divided into lowest quartile ("low SES") or top three quartiles ("high SES"). SES composite scores such as the one used in this study have been used in other previously published studies using cancer registry databases to identify SES disparities in cancer $(2,5,13,14)$.

\section{Data analysis}

The chi-square or Wilcoxon rank sum test was performed for comparisons of demographic and clinical characteristics between groups as classified by SES. Univariate logistic re- gression was used to estimate crude odds ratios (ORs) and 95\% confidence intervals (CIs) for each possible socioeconomic predictor for RAI treatment. To identify independent predictors for RAI treatment, multivariate analysis using a stepwise logistic regression model was used, with forward selection and backward elimination threshold at 0.3 and 0.1 alpha level, respectively. All statistical tests were two-sided, and $p<0.05$ was taken as the level of statistical significance. All analyses were performed using SAS software, version 9.2 (SAS Institute Inc., Cary, NC).

\section{Results}

A total of 11,198 patients with PTC diagnosed between the years 2004 and 2009 were identified from the SEER database. Among them, 9011 patients fit the inclusion criteria for this study. Table 1 shows the demographic, tumor, and treatment characteristics of patients included in this study by SES composite score. In the $<45$-year age group, there was no significant difference in sex, tumor size, tumor extension, solitary versus multifocality, regional nodes examined, and AJCC stage between the low- and high-SES groups. A statistically significant difference was noted in the racial/ethnic makeup of low- and high-SES patients, with a higher percentage of black and Hispanic patients in the low-SES group. Low-SES patients were also more likely to present with positive lymph nodes and to have $>4$ lymph nodes resected. In the $\geq 45$ age group, low-SES patients were significantly more likely to present with advanced AJCC stage, positive lymph nodes, multifocal tumors, extrathyroidal extension, and larger tumors.

Univariate analysis of RAI use by socioeconomic variable can be found in Table 2. Patients $<45$ years of age residing in counties with a higher median household income and higher percent high school education had higher rates of RAI use, while no statistically significant association was found between RAI use and percent insured. RAI use was also significantly higher among patients in counties with a higher SES composite score. In the $\geq 45$ group, patients from counties with a higher median household income and a higher county-level graduation rate had higher rates of RAI use. No significant association was noted between RAI use and insurance status or SES composite score.

Results of the multivariate analysis of RAI use by countylevel median household income, percent high school education, and percent insured can be found in Table 3. Among patients $<45$ years of age, those from counties with a higher median household income had significantly higher rates of RAI use (OR 1.36 [CI 1.09-1.70], $p=0.006$ ), while no significant association was noted between RAI use and percent insured or percent high school education. Among patients $\geq 45$, those residing in counties with a higher education level were associated with higher rates of RAI use (OR 1.27 [CI $1.05-1.54], p=0.015$ ), while county-level insured status was associated with a significantly lower rate of RAI use (OR 0.76 [CI 0.65-0.90], $p=0.002$ ). No statistically significant association was noted between median household income and rate of RAI use.

Multivariate analysis of RAI use by SES composite score is found in Table 4. A higher SES score was associated with higher rates of RAI use in patients $<45$ years of age (OR 1.29 [CI 1.11-1.49], $p<0.001)$, while the association between 
Table 1. Demographic, Pathological, and Treatment Characteristics of Patients with Papillary Thyroid Cancer by Socioeconomic Status and Age (Surveillance, Epidemiology, and End Results, 2004-2009)

\begin{tabular}{|c|c|c|c|c|c|c|c|c|c|c|}
\hline \multirow[b]{3}{*}{ Pathologic features } & \multicolumn{5}{|c|}{$<45$ years } & \multicolumn{5}{|c|}{$\geq 45$ years } \\
\hline & \multicolumn{2}{|c|}{ Low SES } & \multicolumn{2}{|c|}{ High SES } & \multirow[b]{2}{*}{$\mathrm{p}$} & \multicolumn{2}{|c|}{ Low SES } & \multicolumn{2}{|c|}{ High SES } & \multirow[b]{2}{*}{$\mathrm{p}$} \\
\hline & $\mathrm{n}$ & $\%$ & $\mathrm{n}$ & $\%$ & & $\mathrm{n}$ & $\%$ & $\mathrm{n}$ & $\%$ & \\
\hline \multicolumn{11}{|l|}{ Sex } \\
\hline Male & 217 & 19.5 & 491 & 18.2 & \multirow[t]{2}{*}{0.354} & 441 & 28.5 & 1029 & 28.1 & \multirow[t]{2}{*}{0.809} \\
\hline Female & 894 & 80.5 & 2200 & 81.8 & & 1109 & 71.5 & 2630 & 71.9 & \\
\hline \multicolumn{11}{|l|}{ Race/ethnicity } \\
\hline White & 583 & 52.5 & 1876 & 70.0 & \multirow[t]{4}{*}{$<0.001$} & 941 & 60.8 & 2853 & 78.3 & \multirow[t]{4}{*}{$<0.001$} \\
\hline Hispanic & 363 & 32.7 & 360 & 13.4 & & 332 & 21.5 & 285 & 7.8 & \\
\hline Black & 78 & 7.0 & 193 & 7.2 & & 128 & 8.9 & 229 & 6.3 & \\
\hline Asian & 86 & 7.8 & 252 & 9.4 & & 137 & 8.8 & 278 & 7.6 & \\
\hline \multicolumn{11}{|l|}{ Tumor size, mm } \\
\hline Median (IQR) & \multicolumn{2}{|c|}{$23(15-35)$} & 22( & $-33)$ & \multirow{4}{*}{$\begin{array}{l}0.290 \\
0.635\end{array}$} & \multicolumn{2}{|c|}{$23(15-35)$} & 21( & $-32)$ & \multirow{4}{*}{$\begin{array}{l}0.002 \\
0.019\end{array}$} \\
\hline $11-20 \mathrm{~mm}$ & 491 & 44.8 & 1225 & 46.1 & & 682 & 44.7 & 1753 & 48.7 & \\
\hline $21-40 \mathrm{~mm}$ & 438 & 39.9 & 1054 & 39.6 & & 591 & 38.7 & 1321 & 36.7 & \\
\hline$>40 \mathrm{~mm}$ & 168 & 15.3 & 379 & 14.3 & & 254 & 16.6 & 524 & 16.6 & \\
\hline \multicolumn{11}{|l|}{ Tumor } \\
\hline Intrathyroidal & 906 & 81.6 & 2220 & 82.6 & \multirow[t]{2}{*}{0.477} & 1174 & 75.7 & 2869 & 78.4 & \multirow[t]{2}{*}{0.035} \\
\hline Extrathyroidal & 204 & 18.4 & 468 & 17.4 & & 376 & 24.3 & 790 & 21.6 & \\
\hline \multicolumn{11}{|l|}{ Solitary vs. multifocal } \\
\hline Solitary & 575 & 52.7 & 1423 & 53.6 & \multirow[t]{2}{*}{0.600} & 719 & 47.9 & 1845 & 51.7 & \multirow[t]{2}{*}{0.013} \\
\hline Multifocal & 517 & 47.3 & 1232 & 46.4 & & 783 & 52.1 & 1723 & 48.3 & \\
\hline Regional node examined & & & & & & & & & & \\
\hline $0-1$ & 624 & 57.6 & 1592 & 60.6 & 0.091 & 1053 & 69.2 & 2524 & 70.1 & 0.521 \\
\hline$>1$ & 460 & 42.4 & 1037 & 39.4 & & 468 & 30.8 & 1075 & 29.9 & \\
\hline Regional node positive & & & & & & & & & & \\
\hline $0-1$ & 386 & 65.0 & 1046 & 70.4 & 0.015 & 506 & 74.2 & 1283 & 78.7 & 0.018 \\
\hline$>1$ & 208 & 35.0 & 439 & 29.6 & & 176 & 25.8 & 347 & 21.3 & \\
\hline AJCC staging & & & & & & & & & & \\
\hline I & 1094 & 98.6 & 2666 & 99.1 & 0.162 & 506 & 32.6 & 1346 & 36.8 & $<0.001$ \\
\hline II & 15 & 1.4 & 23 & 0.9 & & 390 & 25.2 & 942 & 25.7 & \\
\hline III & & & & & & 420 & 27.1 & 960 & 26.2 & \\
\hline IV & & & & & & 234 & 15.1 & 411 & 11.2 & \\
\hline Lymph node dissection & & & & & & & & & & \\
\hline$>4$ LNs removed & 314 & 28.8 & 648 & 24.4 & 0.005 & 279 & 18.3 & 627 & 17.3 & 0.390 \\
\hline Others & 776 & 71.2 & 2005 & 75.6 & & 1246 & 81.7 & 2998 & 82.7 & \\
\hline
\end{tabular}

AJCC, American Joint Committee on Cancer; IQR, interquartile range; LNs, lymph nodes; SES, socioeconomic status.

Table 2. Univariate Analysis of Radioactive Iodine Use in Patients with Papillary Thyroid Cancer in Association with Socioeconomic Status

\begin{tabular}{|c|c|c|c|c|c|c|c|c|c|c|}
\hline \multirow[b]{3}{*}{ Socioeconomic status } & \multicolumn{5}{|c|}{$<45$ years } & \multicolumn{5}{|c|}{$\geq 45$ years } \\
\hline & \multicolumn{2}{|c|}{ None } & \multicolumn{2}{|c|}{$R A I$} & \multirow[b]{2}{*}{$\mathrm{p}$} & \multicolumn{2}{|c|}{ None } & \multicolumn{2}{|c|}{$R A I$} & \multirow[b]{2}{*}{$\mathrm{p}$} \\
\hline & $\mathrm{n}$ & $\%$ & $\mathrm{n}$ & $\%$ & & $\mathrm{n}$ & $\%$ & $\mathrm{n}$ & $\%$ & \\
\hline \multicolumn{11}{|l|}{ Median income } \\
\hline Low & 296 & 41.4 & 423 & 58.9 & \multirow[t]{2}{*}{$<0.001$} & 427 & 40.7 & 623 & 59.3 & \multirow[t]{2}{*}{0.020} \\
\hline High & 1035 & 34.0 & 2001 & 66.0 & & 1506 & 36.8 & 2589 & 63.2 & \\
\hline \multicolumn{11}{|l|}{ With insurance } \\
\hline Low & 426 & 36.7 & 732 & 63.3 & \multirow[t]{2}{*}{0.251} & 573 & 36.5 & 998 & 63.5 & \multirow[t]{2}{*}{0.282} \\
\hline High & 905 & 34.8 & 1692 & 65.2 & & 1360 & 38.1 & 2214 & 61.9 & \\
\hline \multicolumn{11}{|l|}{ HS education } \\
\hline Low & 430 & 38.8 & 678 & 61.2 & \multirow[t]{2}{*}{0.005} & 611 & 39.6 & 931 & 60.4 & \multirow[t]{2}{*}{0.047} \\
\hline High & 901 & 34.0 & 1746 & 66.0 & & 1322 & 36.7 & 2281 & 63.3 & \\
\hline \multicolumn{11}{|l|}{ SES } \\
\hline Low & 434 & 39.5 & 666 & 60.5 & \multirow[t]{2}{*}{$<0.001$} & 600 & 39.3 & 927 & 60.7 & \multirow[t]{2}{*}{0.098} \\
\hline High & 897 & 33.7 & 1758 & 66.3 & & 1333 & 36.8 & 2285 & 63.2 & \\
\hline
\end{tabular}

HS, high school; RAI, radioactive iodine. 
Table 3. Multivariate Analysis of Radioactive Iodine Use in Patients with Papillary Thyroid Cancer (Median Income, Percent with Insurance, Percent with High School Education)

\begin{tabular}{|c|c|c|c|c|}
\hline \multirow[b]{2}{*}{ Predictor } & \multicolumn{4}{|c|}{ Use of RAI } \\
\hline & $\begin{array}{c}<45 \text { years } \\
\text { OR }[95 \% \text { CI] }\end{array}$ & $\mathrm{p}$ & $\begin{array}{c}\geq 45 \text { years } \\
\text { OR }[95 \% \text { CI }]\end{array}$ & $\mathrm{p}$ \\
\hline \multicolumn{5}{|l|}{ Median income } \\
\hline $\begin{array}{l}\text { Low } \\
\text { High }\end{array}$ & & & & \\
\hline \multirow{2}{*}{\multicolumn{5}{|c|}{ With insurance }} \\
\hline Low & & & & \\
\hline High & $0.89[0.73-1.09]$ & 0.272 & $0.76[0.65-0.90]$ & 0.002 \\
\hline \multicolumn{5}{|l|}{ HS education } \\
\hline $\begin{array}{l}\text { Low } \\
\text { High }\end{array}$ & $1.12[0.88-1.40]$ & 0.347 & $1.27[1.05-1.54]$ & 0.015 \\
\hline \multicolumn{5}{|c|}{ Solitary vs. multifocal } \\
\hline Multifocal & $1.27[1.10-1.45]$ & $<0.001$ & & \\
\hline \multicolumn{5}{|l|}{ Tumor } \\
\hline $\begin{array}{l}\text { Intrathyroidal } \\
\text { Extrathyroidal }\end{array}$ & $1.46[1.21-1.77]$ & $<0.001$ & & \\
\hline \multirow{2}{*}{\multicolumn{5}{|c|}{$\begin{array}{l}\text { AJCC stage } \\
\text { I }\end{array}$}} \\
\hline & & & & \\
\hline III & & & $1.45[1.25-1.68]$ & $<0.001$ \\
\hline IV & & & $1.44[1.20-1.75]$ & $<0.001$ \\
\hline
\end{tabular}

A stepwise procedure was used to select independent predator for RAI treatment in the multivariate logistic regression model (entry threshold of 0.3 and stay threshold of 0.1). The median income, with insurance, and HS education variables were forced into the model. $\mathrm{CI}$, confidence interval; OR, odds ratio.

SES score and RAI use in patients $\geq 45$ years of age approached statistical significance (OR 1.13 [CI 1.00-1.28], $p=0.053)$.

A total of 1168 patients were noted to have positive lymph nodes at the time of diagnosis, including 645 (17\%) in the $<45$-year age group and $523(10 \%)$ in the $\geq 45$-year age group. On univariate analysis of RAI use by SES among patients with positive lymph nodes, no significant difference was noted between low- and high-income, insurance status, or percent high school education groups in either the $<45$ or $\geq 45$ age groups.

\section{Discussion}

This study demonstrates population-level SES disparities in the presentation and treatment of PTC. Patients $<45$ years of age in the low-SES group were more likely to present with lymph node involvement. No significant difference was

Table 4. Multivariate Analysis of Radioactive Iodine Use in Patients with Papillary Thyroid Cancer (Socioeconomic Status Composite Score)

\begin{tabular}{|c|c|c|c|c|}
\hline \multirow[b]{2}{*}{ Predictor } & \multicolumn{4}{|c|}{ Use of $R A I$} \\
\hline & $\begin{array}{c}<45 \text { years } \\
\text { OR }[95 \% \text { CI] }\end{array}$ & $\mathrm{p}$ & $\begin{array}{c}\geq 45 \text { years } \\
\text { OR }[95 \% \text { CI] }\end{array}$ & $\mathrm{p}$ \\
\hline \multicolumn{5}{|l|}{ SES } \\
\hline Low & & & & \\
\hline High & 1.29 [1.11-1.49] & $<0.001$ & $1.13[1.00-1.28]$ & 0.053 \\
\hline \multicolumn{5}{|c|}{ Solitary vs. multifocal } \\
\hline Multifocal & $1.26[1.10-1.45]$ & $<0.001$ & & \\
\hline \multicolumn{5}{|l|}{ Tumor } \\
\hline Extrathyroidal & $1.47[1.22-1.78]$ & $<0.001$ & & \\
\hline \multicolumn{5}{|l|}{ AJCC stage } \\
\hline II & & & $1.27[1.10-1.47]$ & 0.001 \\
\hline III & & & $1.45[1.25-1.68]$ & $<0.001$ \\
\hline IV & & & $1.45[1.20-1.75]$ & $<0.001$ \\
\hline
\end{tabular}


noted in AJCC stage in this age group, reflecting that both groups had similar rates of distant metastases at presentation. Among those $\geq 45$ years of age, low-SES patients were more likely to present with advanced AJCC stage, positive lymph nodes, multifocal tumors, extrathyroidal extension, and larger tumors compared with high-SES patients. These findings are in line with a previous report by Lim et al., where thyroid cancer patients presenting to a county hospital had significantly more advanced stage at presentation compared with those presenting to a private hospital (6). Similar findings have been previously reported for a variety of other cancer sites, underscoring the presence of SES disparities in cancer surveillance, screening, and access to care.

This study demonstrates that SES has a significant impact on the use of adjuvant RAI for patients with PTC. Median household income appears to be the strongest determinant of the disparities noted in this study. Patients in the $<45$-year and $\geq 45$-year age groups residing in counties with a higher median household income were significantly more likely to receive RAI on univariate analysis. After adjusting for demographic-, patient-, and tumor-related factors in a multivariate model, high median household income was associated with high RAI use in the $<45$ age group alone. A similar trend was noted when median household income, high school graduation rate, and insurance status were combined into an SES composite score. We found that high-SES patients $<45$ years of age had a $29 \%$ higher likelihood of receiving RAI than low-SES patients. While a similar association was noted between SES score and RAI in the $\geq 45$ group, this finding did not reach statistical significance.

The finding that younger patients are more susceptible to SES disparities in use of RAI warrants further investigation. It has been demonstrated that young adult patients have less adherence to medical treatment for several chronic diseases, including cancer $(15,16)$. Furthermore, young adults are almost twice as likely to lack health insurance compared with older adults, and the number of uninsured adults across all ages has increased over the last 10 years $(17,18)$. A lack of health insurance reflects less access to care, and the financial burden of expensive medical care can limit a patient's adherence to treatment. In younger patients of low SES, this may be further exacerbated by lack of support networks and limited financial resources.

While the indications for adjuvant RAI remain controversial, its use has increased sharply over the last two decades (10). The American Thyroid Association guidelines recommend the use of RAI after total thyroidectomy in all T3 or greater primary tumors, and selective use in patients with intrathyroidal tumor $>1 \mathrm{~cm}$ in size, or evidence of nodal metastases (9). However, it has been demonstrated that RAI use is influenced by several factors unrelated to disease severity $(10,19)$. In a recent study using the National Cancer Database, Haymart et al. demonstrated that adjuvant RAI is more commonly used in high-volume hospitals and less commonly among African Americans, females, and patients without private insurance (10). They found that patient and tumor characteristics accounted for only $21 \%$ of variation in RAI use and that hospital characteristics accounted for $29 \%$ of variation in use. Differences in RAI use by geographic region of the United States (20), as well as a higher use of RAI by physicians with access to a tumor board (21), have also been demonstrated.
The present study identifies SES as an additional factor influencing the use of adjuvant RAI for PTC. The differences in RAI use noted in this study may reflect the difficulty that low-SES patients have in navigating multidisciplinary cancer care in general. Patients in low-SES communities often have limited financial resources and lack of support, preventing them from completing their recommended treatment course or follow-up care (16). This was demonstrated recently in patients with breast cancer, where rates of adherence to adjuvant tamoxifen were found to be significantly lower in patients of low SES (22).

It is important to note that the findings from this study do not necessarily suggest that low-SES patients with PTC are being undertreated. Given the lack of consensus on the use of RAI and significant treatment variation, it is also possible to interpret these findings as evidence of overtreatment among higher SES groups. A recent study by Nixon et al. demonstrated that early-stage and advanced-stage PTC patients not treated with RAI had a 5-year recurrence-free survival of $>97 \%$ and $>90 \%$, respectively (23). Another series of 1298 patients with differentiated thyroid cancer by Schvartz et al. showed no survival benefit of adjuvant RAI for low-risk thyroid cancer (24). These findings suggest that more aggressive treatment among patients in the high-SES groups may not be warranted, particularly when the risk of long-term complications (25) and second primary tumors $(26,27)$ is not insignificant. Further research is needed to better define the indications for adjuvant RAI in the treatment of PTC.

This study has several limitations. Individual-level SES data are not collected in the SEER database, and the use of county-level socioeconomic determinants presents the possibility of ecological bias. However, several previous studies have demonstrated that regional measures of SES such as median household income correlate well with individual measures (11,28-30). Another limitation is the use of U.S. census data from 2000 to determine measures of SES. It is possible that county-level SES may have changed in the time leading up to or during the study period.

In conclusion, this study demonstrates that low SES is associated with more advanced PTC at presentation and a lower rate of adjuvant RAI after total thyroidectomy. Young patients from areas with a low median household income experience the lowest rates of adjuvant RAI use. Future studies are needed to address disparities in the presentation and treatment of PTC, to determine indications for the use of adjuvant RAI, and to ensure appropriate, evidence-based care across the socioeconomic spectrum.

\section{Author Disclosure Statement}

No competing financial interests exist.

\section{References}

1. Ward E, Jemal A, Cokkinides V, Singh GK, Cardinez C, Ghafoor A, Thun M 2004 Cancer disparities by race/ethnicity and socioeconomic status. CA Cancer J Clin 54:78-93.

2. Yin D, Morris C, Allen M, Cress R, Bates J, Liu L 2010 Does socioeconomic disparity in cancer incidence vary across racial/ethnic groups? Cancer Causes Control 21:1721-1730.

3. Wudel LJ Jr, Chapman WC, Shyr Y, Davidson M, Jeyakumar A, Rogers SO Jr, Allos T, Stain SC 2002 Disparate 
outcomes in patients with colorectal cancer: effect of race on long-term survival. Arch Surg 137:550-554; discussion 554-556.

4. Morris LG, Sikora AG, Tosteson TD, Davies L 2013 The increasing incidence of thyroid cancer: the influence of access to care. Thyroid 23:885-891.

5. Li N, Du XL, Reitzel LR, Xu L, Sturgis EM 2013 Impact of enhanced detection on the increase in thyroid cancer incidence in the United States: review of incidence trends by socioeconomic status within the surveillance, epidemiology, and end results registry, 1980-2008. Thyroid 23: 103-110.

6. Lim II, Hochman T, Blumberg SN, Patel KN, Heller KS, Ogilvie JB 2012 Disparities in the initial presentation of differentiated thyroid cancer in a large public hospital and adjoining university teaching hospital. Thyroid 22:269274.

7. Siu S, McDonald JT, Rajaraman M, Franklin J, Paul T, Rachinsky I, Morrison D, Imran SA, Burrell S, Hart R, Driedger A, Badreddine M, Yoo J, Corsten M, Van Uum S 2014 Is lower socioeconomic status associated with more advanced thyroid cancer stage at presentation? A study in two Canadian centers. Thyroid 24:545-551.

8. Sawka AM, Brierley JD, Tsang RW, Thabane L, Rotstein L, Gafni A, Straus S, Goldstein DP 2008 An updated systematic review and commentary examining the effectiveness of radioactive iodine remnant ablation in welldifferentiated thyroid cancer. Endocrinol Metab Clin North Am 37:457-480, x.

9. Cooper DS, Doherty GM, Haugen BR, Kloos RT, Lee SL, Mandel SJ, Mazzaferri EL, McIver B, Pacini F, Schlumberger M, Sherman SI, Steward DL, Tuttle RM; American Thyroid Association (ATA) Guidelines Taskforce on Thyroid Nodules and Differentiated Thyroid Cancer 2009 Revised American Thyroid Association management guidelines for patients with thyroid nodules and differentiated thyroid cancer. Thyroid 19:1167-1214.

10. Haymart MR, Banerjee M, Stewart AK, Koenig RJ, Birkmeyer JD, Griggs JJ 2011 Use of radioactive iodine for thyroid cancer. JAMA 306:721-728.

11. Edge SB, Byrd DR, Compton CC, Fritz AG, Greene FL, Trotti A (Eds) 2010 AJCC Cancer Staging Manual, 7th ed. Springer, New York.

12. Krieger N, Chen JT, Waterman PD 2010 Decline in US breast cancer rates after the Women's Health Initiative: socioeconomic and racial/ethnic differentials. Am J Public Health 100 Suppl 1:S132-S139.

13. Yost K, Perkins C, Cohen R, Morris C, Wright W 2001 Socioeconomic status and breast cancer incidence in California for different race/ethnic groups. Cancer Causes Control 12:703-711.

14. Harper S, Lynch J, Meersman SC, Breen N, Davis WW, Reichman ME 2008 An overview of methods for monitoring social disparities in cancer with an example using trends in lung cancer incidence by area-socioeconomic position and race-ethnicity, 1992-2004. Am J Epidemiol 167:889-899.

15. Trevino KM, Fasciano K, Prigerson HG 2013 Patientoncologist alliance, psychosocial well-being, and treatment adherence among young adults with advanced cancer. J Clin Oncol 31:1683-1689.

16. Rolnick SJ, Pawloski PA, Hedblom BD, Asche SE, Bruzek RJ 2013 Patient characteristics associated with medication adherence. Clin Med Res 11:54-65.
17. Cohen RA, Bloom B 2010 Access to and utilization of medical care for young adults ages 20-29 years: United States, 2008. NCHS Data Brief 2010:1-8.

18. Driscoll AK, Bernstein AB 2012 Health and access to care among employed and unemployed adults: United States, 2009-2010. NCHS Data Brief 2012:1-8.

19. Papaleontiou M, Banerjee M, Yang D, Sisson JC, Koenig RJ, Haymart MR 2013 Factors that influence radioactive iodine use for thyroid cancer. Thyroid 23:219-224.

20. Haymart MR, Muenz DG, Stewart AK, Griggs JJ, Banerjee M 2013 Disease severity and radioactive iodine use for thyroid cancer. J Clin Endocrinol Metab 98:678-686.

21. Haymart MR, Banerjee M, Yang D, Stewart AK, Koenig RJ, Griggs JJ 2013 The role of clinicians in determining radioactive iodine use for low-risk thyroid cancer. Cancer 119:259-265.

22. Lin JH, Zhang SM, Manson JE 2011 Predicting adherence to tamoxifen for breast cancer adjuvant therapy and prevention. Cancer Prev Res (Phila) 4:1360-1365.

23. Nixon IJ, Ganly I, Patel SG, Palmer FL, Di Lorenzo MM, Grewal RK, Larson SM, Tuttle RM, Shaha A, Shah JP 2013 The results of selective use of radioactive iodine on survival and on recurrence in the management of papillary thyroid cancer, based on Memorial Sloan-Kettering Cancer Center risk group stratification. Thyroid 23:683-694.

24. Schvartz C, Bonnetain F, Dabakuyo S, Gauthier M, Cueff A, Fieffé S, Pochart JM, Cochet I, Crevisy E, Dalac A, Papathanassiou D, Toubeau M 2012 Impact on overall survival of radioactive iodine in low-risk differentiated thyroid cancer patients. J Clin Endocrinol Metab 97:1526-1535.

25. Lee SL 2010 Complications of radioactive iodine treatment of thyroid carcinoma. J Natl Compr Canc Netw 8:12771286; quiz 1287.

26. Sawka AM, Thabane L, Parlea L, Ibrahim-Zada I, Tsang RW, Brierley JD, Straus S, Ezzat S, Goldstein DP 2009 Second primary malignancy risk after radioactive iodine treatment for thyroid cancer: a systematic review and metaanalysis. Thyroid 19:451-457.

27. Iyer NG, Morris LG, Tuttle RM, Shaha AR, Ganly I 2011 Rising incidence of second cancers in patients with lowrisk (T1N0) thyroid cancer who receive radioactive iodine therapy. Cancer 117:4439-4446.

28. Krieger N, Chen JT, Waterman PD, Rehkopf DH, Subramanian SV 2005 Painting a truer picture of US socioeconomic and racial/ethnic health inequalities: the Public Health Disparities Geocoding Project. Am J Public Health 95:312-323.

29. Krieger N, Chen JT, Waterman PD, Soobader MJ, Subramanian SV, Carson R 2002 Geocoding and monitoring of US socioeconomic inequalities in mortality and cancer incidence: does the choice of area-based measure and geographic level matter? The Public Health Disparities Geocoding Project. Am J Epidemiol 156:471-482.

30. Krieger N, Williams DR, Moss NE 1997 Measuring social class in US public health research: concepts, methodologies, and guidelines. Annu Rev Public Health 18:341-378.

Address correspondence to: Jose P. Zevallos, MD

Bobby R. Alford Department of Otolaryngology/ Head and Neck Surgery Baylor College of Medicine One Baylor Plaza, NA 102 Houston, TX 77030

E-mail: zevallos@bcm.edu 